First publ. in: Toxicology Letters 131 (2002), 1-2, pp. 83-95

\title{
Evaluation of immune functions of rainbow trout (Oncorhynchus mykiss) — how can environmental influences be detected?
}

\author{
B. Köllner ${ }^{\mathrm{a}, *}$, B. Wasserrab ${ }^{\mathrm{b}}$, G. Kotterba ${ }^{\mathrm{c}}, \mathrm{U}$. Fischer ${ }^{\mathrm{c}}$ \\ ${ }^{a}$ Federal Research Centre for Virus Diseases of Animals, Institute of Diagnostic Virology, Insel Riems, Germany \\ ${ }^{\mathrm{b}}$ Environmental Toxicology, University of Konstanz, Konstanz, Germany \\ ${ }^{\mathrm{c}}$ Federal Research Centre for Virus Diseases of Animals, Institute of Infectology, Insel Riems, Germany
}

\begin{abstract}
In fish, the first line of defense against infectious microorganisms is based on a broad range of nonspecific humoral and cellular immune mechanisms ('innate immunity') which without prior specific activation can act in forming a more static barrier (Fish Shellfish Immunol. 10 (2000) 243; Dev. Comp. Immunol. 25 (2001) 827). This natural resistance is normally effective enough to protect fish from infectious diseases until specific immune responses are being induced (Fig. 1; Dev. Comp. Immunol. 25 (2001) 841). Healthy fish exhibit both nonspecific and specific immune responses depending directly on environmental temperature. Pollution of the natural aquatic environment with industrial or agricultural sewage is an important immunosuppressing factor resulting in higher susceptibility to infectious diseases. To date, the possible immunotoxicity of a substance is evaluated using quantification of humoral factors like lysozyme, complement, C-reactive protein or total immunoglobulins but less often using functional assays. Furthermore, most of the functional assays (phagocytosis, respiratory burst, proliferative response) are based on the measurement of the response of resting but not of specific activated immune cells. However, the physiological responses of the immune system to an infection are based on a complex, stepwise activation and proliferation, especially of the specific immune functions after first contact to the microorganisms. In this report we describe in vitro methods for the evaluation of cellular immune functions of different leukocyte populations after specific in vivo triggering of the immune system. Parameters to be evaluated are activation and proliferation of leukocyte populations, phagocytosis and respiratory burst, secretion of antigen-specific antibodies and specific cell-mediated cytotoxicity. Furthermore, challenge models with bacterial (Aeromonas salmonicida) and viral pathogens (Viral Haemorrhagic Septicemia Virus, VHSV) are presented.
\end{abstract}

Keywords: Rainbow trout; Immune functions; Measurement of environmental influences; Immunotoxicology

\section{Introduction}

* Corresponding author. Tel.: + 49-38351-7208; fax: + 4938351-7219.

Fish health affects many aspects of our life. E-mail address: bernd.koellner@rie.bfav.de (B. Köllner). First, it reflects the quality of our aquatic environ- 
ment and secondly, it is the basis for an efficient production of high quality fish in aquaculture providing food for an increasing human population. However, the increasing human population is the main source of pollution of the aquatic environment affecting fish and human health as well (Zelikoff, 1998).

The evaluation of aquatic environmental pollution by chemicals or drugs regarding potential adverse effects on immunocompetence of fish depends on standardized test systems. Most immunotoxicological tests yield only one, or a limited number of parameters or functions, socalled 'biomarkers' (Beaman et al., 1999; Walker, 1998). Moreover, they only determine the overall ability of the resting immune system to react but fail to investigate the influence on a specifically stimulated immune response (Zelikoff et al., 2000; Twerdok et al., 1996). Commonly used tests are determining the amount of humoral factors of the nonspecific (lysozyme, C-reactive protein, complement) and the specific (immunoglobulin M, IgM) immune system, and some functional assays are applied to measure the phagocytotic activity or the proliferative response of immune cells. Complex, stimulated immune functions are not examined (Langezaal et al., 2001; Luebke et al., 1997; Luster et al., 1992, 1993; Smith et al., 1999).

However, pollutants seldom affect a single parameter or function. And, as there is no effective way to predict the impact of small or moderate changes on host resistance in multiple immunological parameters, an increase or decrease of one or a limited number of parameters does not reflect the influence of a pollutant on the complex immune response involved in resistance to infections or cancer. The interactions between different immune mechanisms, a possible overreaction of the immune system, or the compensation of a suppressed immune function by another cannot be discovered in this way (Zelikoff et al., 1995; Keil et al., 1999, 2001).

A further problem is the limited knowledge of immune functions in fish involved in resistance to infections or cancer. Several aspects of antigen recognition, of the interaction between immune cells, directly or via cytokines, or of the regulation of effector mechanisms namely specific antibody secretion or cell-mediated cytotoxicity are not fully understood (Fig. 1), since only limited number of tools are available to investigate these immune functions in fish. And finally, the immune response of fish depends directly on internal (age, sexual cycle) but also on external environmental (temperature, season) factors (Magnadottir et al., 1999; Bly et al., 1997). These factors greatly influence immune functions ranging from an almost non-reactive to a highly reactive state of all immune functions (Zapata and Amemiya, 2000; Zapata et al., 1992).

To determine the influence of pollution on the immune response to infection, vaccination and cancer, including the impact of stress as a side effect several methods were developed in the last decade (Arkoosh et al., 1998). Stress factors such as high population density and suboptimal environmental conditions are one of the major problems in aquaculture resulting in increased susceptibility of farmed fish to infectious diseases. Some of the influences are comparable to the situation of a polluted natural ecological system. In order to prevent dramatic loss in fish production due to infectious diseases an extensive vaccination program has been introduced in aquaculture (Gudding et al., 1999; Ellis, 1997). Unfortunately, potency of these vaccines is not sufficient, and one reason for their limited usefulness or benefit seems to be based on the abovementioned stress and the resulting immunosuppression (Anderson, 1997).

The methods discussed in this report were developed to investigate natural immune responses to infectious agents (Köllner and Kotterba, 2002; Fischer et al., 1998; Secombes, 1990; Nagelkerke et al., 1990). However, these methods can also be used to determine suppressing effects of pollutants on complex immune functions of fish by/due to:

1. Induction of a defined immune response to defined stimulants.

2. Evaluation of the induced stimulation of different parts of the immune system from the first activation of immune cells to resistance against infectious microorganisms as a result of a complex immune response.

3. Sensitivity of these methods which allow the detection of effects on distinct immune func- 
tions before a total loss (death of the effector cell) or a strong decrease or increase of the function has occurred.

\section{Preliminary remarks to measurement of immune functions possibly affected or disturbed by pollutants}

The influence of aquatic pollutants on immune functions can be determined by exposing the fish to the test substance followed by a standardized in vivo stimulation of the immune response (preexposure) or by exposing the fish to the test substance simultaneously with the in vivo stimulation (co-exposure) (Fig. 2). The advantage of a standardized stimulation is the induction of a defined immune response in which the difference between a mock and a real exposure to a certain pollutant can be determined. In addition, several pollutants can be compared. In contrast to the in vitro determination of single cellular based functions such as phagocytosis and respiratory burst the in vivo stimulation of the entire immune system reflects the capacity of complex immune functions. On the other hand, these complex immune reactions can be characterized in more detail using stimulants of known reactivity (bacteria mitogens, allogeneic cells, virus derived peptides, Fig. 2) yielding a stimulation of defined leukocyte subpopulations.

Trout leukocytes can be separated into subpopulations by physical (density gradient separation) and immunological (immunomagnetic separation using monoclonal antibodies against specific cell surface markers) methods (Fischer and Köllner, 1994; Marsden et al., 1995). Due to the strong dependence of almost all immune functions of fish on environmental temperature, the cultivation of trout leukocytes has to be carried out at 15$20{ }^{\circ} \mathrm{C}$ in all in vitro assays (Hardie et al., 1994; Novoa et al., 1996a,b).
Nonspecific, innate
immune system
Specific, adapted

immune system

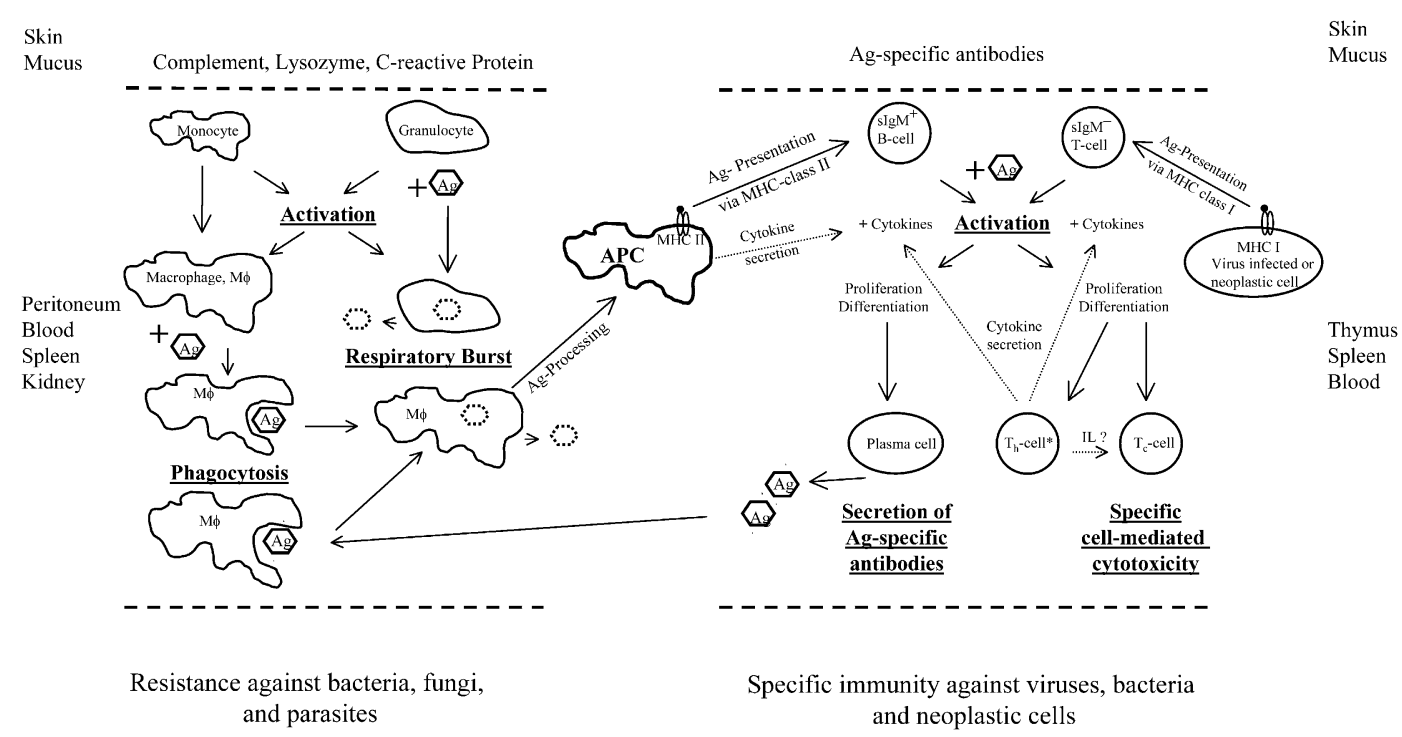

Fig. 1. Schematic overview of known immune functions of bony fish. For detailed information see text. Dotted arrows indicate functions which are predicted from proliferation assays only. Abbreviations: Ag, antigen; APC, antigen presenting cell; MHC, major histocompatibility complex; $\mathrm{M}$, macrophage; sIgM, surface immunoglobulin $\mathrm{M} ; \mathrm{T}_{\mathrm{h}}$-cell, helper $\mathrm{T}_{\text {lymphocytes; }} \mathrm{T}_{\mathrm{c}}$-cell, cytotoxic T-lymphocytes (*Both are predicted from functional assays only, not shown as specific cell population). 


\section{Resistance against bacterial or viral infection}

The resistance against bacterial or immunity against viral infection is the result of a complex immune response.

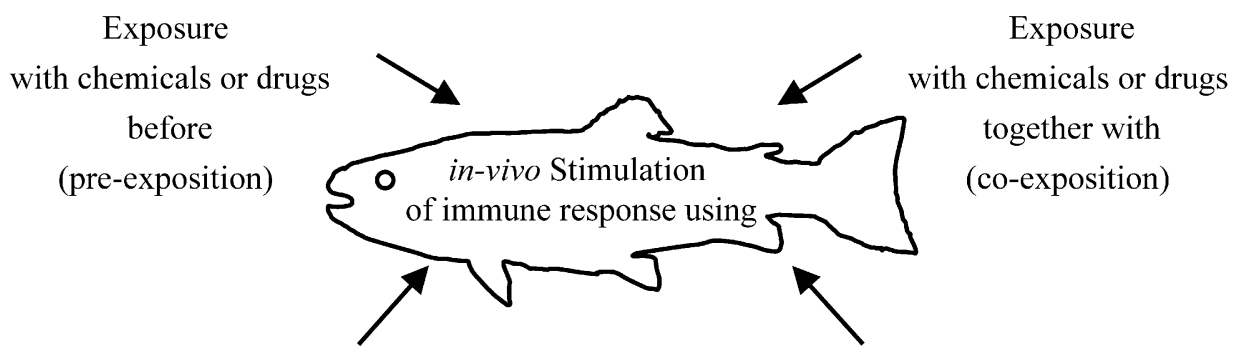

Infection with $A$. salmonicida

Infection with VHSV

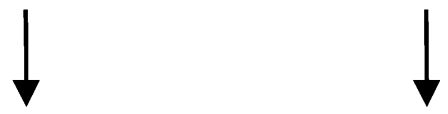

to determine

resistance of trout against infectious microorganisms

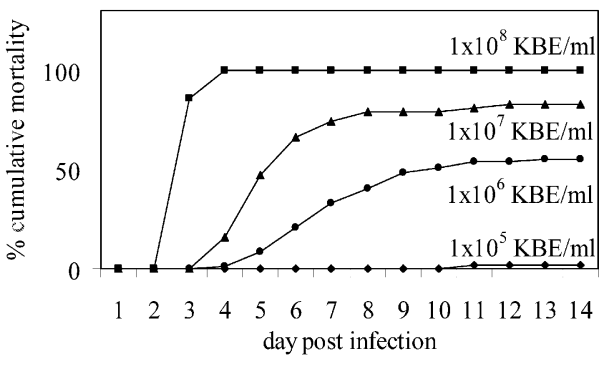

Cumulative mortality of healthy, unaffected trout after infection with different doses of A. salmonicida

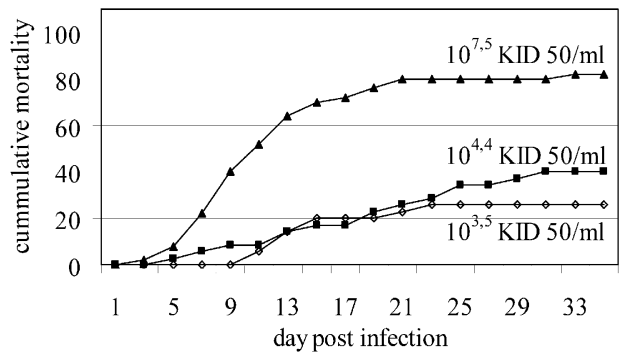

Cumulative mortality of healthy, unaffected trout after infection with different doses of VHSV

Fig. 2. Suggested methods to assay possible toxic effects of aquatic pollutants. The exposure to chemicals or drugs can be performed before (pre-exposure) or simultaneously (co-exposure) with in vivo stimulation using bacteria, mitogens, allogeneic cells or virus derived peptides to stimulate different leukocyte populations. The basic immune response had previously been induced in vivo. Single immune functions of separated leukocyte populations are determined by different in vitro assays with or without in vitro priming using appropriate stimulants.

\section{Evaluation of natural resistance or immunity against bacterial and viral infection}

The resistance or immunity against bacterial or viral infection is the result of the efficient and complex immune response (Fig. 1; Ellis, 2001; Jones, 2001; Smith et al., 2000). This immune response can be decreased or inhibited by immunotoxic chemicals or drugs starting with a loss of regulative compensation of affected immune cells or disturbed immune functions. Consequently, the correct determination of possible immunotoxicity of a substance is based on the measurement of the inhibitory influence on the 
survival rate after infection with virulent strains of bacteria or viruses (Zelikoff, 1998; Zelikoff et al., 2000).

A useful test to determine the resistance against a bacterial or viral infection is shown in Fig. 3 . For these tests, highly virulent bacterial or virus strains which cause a mortality in untreated fish of a defined age under defined environmental conditions should be used. The cumulative mortality after infection is easy to determine and can be adjusted to a value recommended for testing of possible immunotoxic substances (Fig. 3). As stated before, the immunotoxic effect of aquatic pollutants can be determined using either a preor a co-exposure method. To minimize inhibitory effects of the pollutant on bacteria or viruses and to ensure an exact dose of microorganisms an intraperitoneal rather than water-born infection should be used.
The mortality test reflects a more general toxic effect on the complex immune system. However, no data can be obtained on the 'level' at which the immune system is affected. To answer this question more detailed tests, as described below, have to be performed.

\section{Activation of leukocytes and leukocyte subpopulations}

The immune response against foreign antigens always starts with an activation and subsequent proliferation of leukocyte populations, which will be involved in the immune response (Rycyzyn et al., 1998). The first cells to be activated are monocytes/macrophages and neutrophilic granulocytes followed by $\operatorname{sIgM}^{+}$B- and $\operatorname{sIgM}^{-}$T-lymphocytes

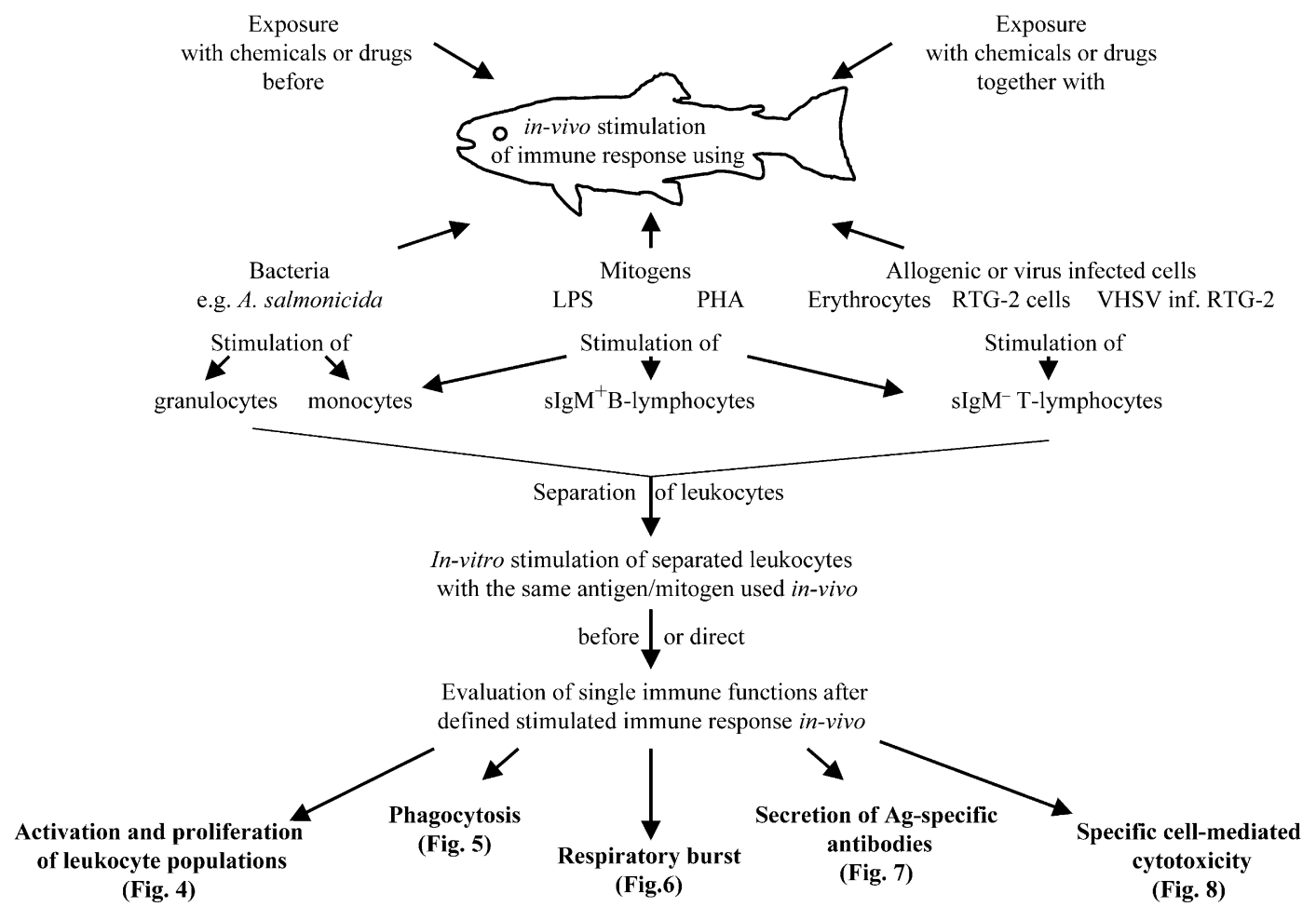

Fig. 3. Suggested evaluation model for the immunotoxic impact of pollutants by testing the altered resistance to infection with pathogenic microorganisms (Aeromonas salmonicida; Viral Haemorrhagic Septicemia Virus, VHSV). The resistance is the result of a complex immune response induced by in vivo infection with microorganisms simultaneously with or after exposure of fish to pollutants. The basic mortality of unaffected fish depends on the dose of infectious microorganisms. Abbreviations: TCD 50, tissue culture infectious dose; CFU, colony forming units. 
Measurement of activation and proliferation of leukocytes

The activation of leucocytes is the fist cellular reaction in every immune response. Depending on the antigen leukocyte subpopulations are specifically activated and proliferate.

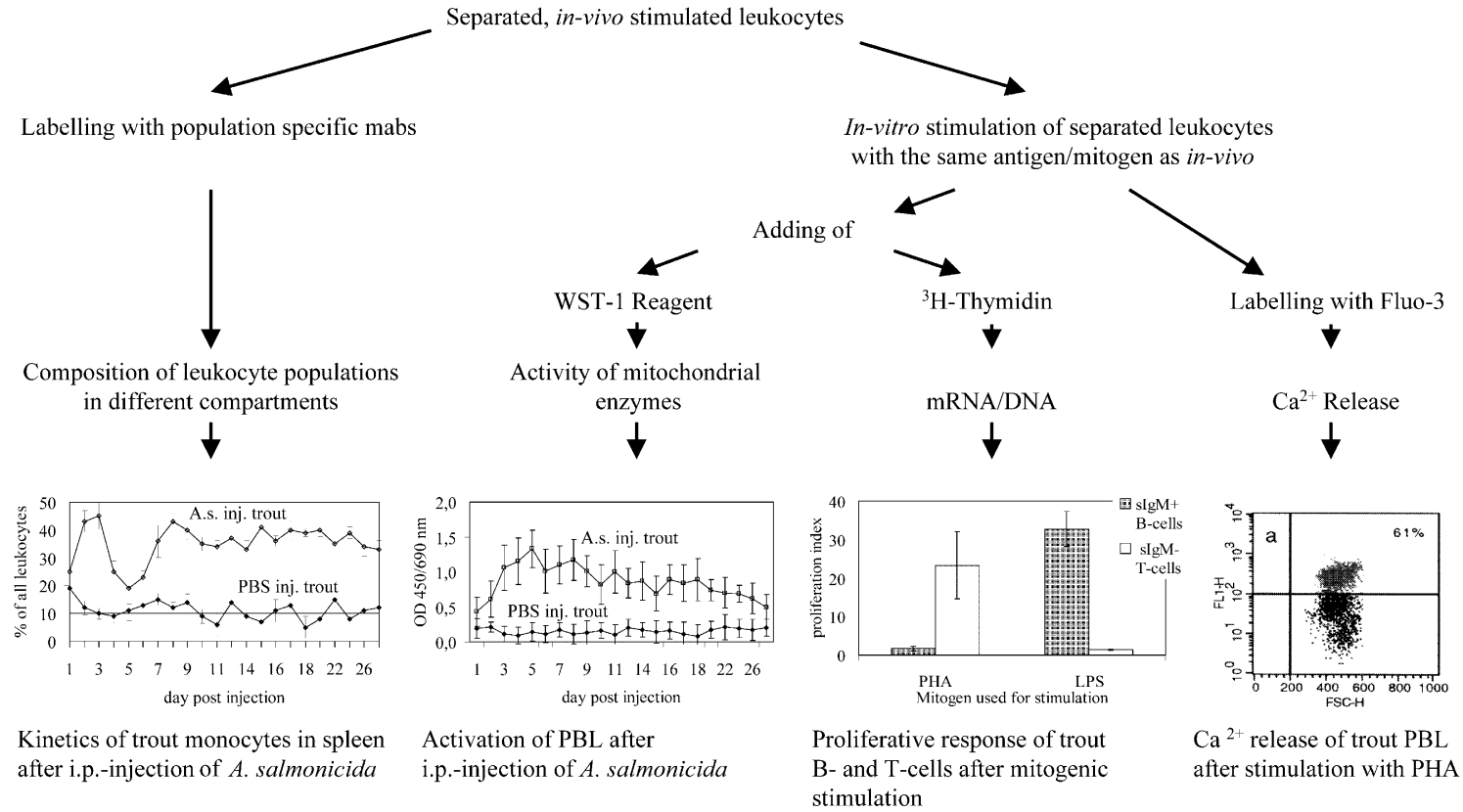

Fig. 4. Methods to determine activation and proliferation of leukocyte populations. In vivo stimulated leukocytes were cultivated in vitro with or without an additional stimulus. The activation of mitochondrial reductases as a proliferation marker can be determined using WST-1 (Blohm et al., submitted for publication). Another proliferation marker is the direct incorporation of ${ }^{3} \mathrm{H}$-thymidine (Marsden et al., 1995). The labeling of cells with Flou-3 is an indicator for $\mathrm{Ca}^{2+}$ influx which is a marker for the activation of cell metabolism (Verburg-Van Kemenade et al., 1998). The complex response of different leukocyte populations after stimulation in vivo can be estimated by staining with population-specific monoclonal antibodies in flow cytometry (Köllner and Kotterba, 2002). The diagrams show examples of typical responses of trout leukocytes after in vivo stimulation.

(Fig. 1). The activation depends on several internal (age, sexual cycle, antigenicity of invading antigen, health status) and external (water temperature, season) factors (Bly et al., 1997). Inhibition (or suppression) of the ability to activate leukocyte populations leads to a 'no-responsestatus' of the immune system to the pathogen finally resulting in fatal outcome. Methods for evaluation of activation/proliferation of leukocytes are based on different principles (Fig. 4):

1. measurement of the activity of mitochondrial enzymes using specific substrates (WST-1)

2. measurement of the influx of $\mathrm{Ca}^{2+}$ ions into the cytoplasm using a fluorescent marker

3. detection of incorporation of ${ }^{3} \mathrm{H}$-thymidine into cellular DNA
4. detection of the percentage of leukocyte populations in lymphatic compartments.

These methods are sensitive enough to differentiate (discriminate) the reactivity of leukocytes and leukocyte populations to different stimulants or different environmental temperatures and should therefore also be useful in detecting stimulating or inhibiting effects of aquatic pollutants.

\section{Phagocytosis}

Phagocytosis is an nonspecific immune function whereby phagocytes internalize, kill, and digest invading microorganisms. It has been shown in different fish species that circulating monocytes/ 
macrophages and granulocytes form an integral immune defense network capable of neutralizing a variety of invading pathogens and their secreted soluble factors by phagocytosis without prior activation (Fig. 1) (Ainsworth, 1992; Secombes and Fletcher, 1992; Dannevig et al., 1994). However, it has also been shown that the activation of monocytes by LPS or opsonization of microorganisms through complement components or antibodies leads to increased phagocytosis (Gudmundsdottir et al., 1995; Solem et al., 1995).

Furthermore, phagocytosis is the first step in the accessory function of monocytes and macrophages to stimulate lymphocyte response. Phagocytosed particles are processed and presented as antigenic peptides in association with class II MHC molecules on the surface of phagocytes. Subsequently, soluble mediators involved in lymphocyte activation like IL-1 $\beta$ are secreted (Fig. 1) (Hong et al., 2001). Inhibition of phagocytosis disturbs the clearance of bacteria, the processing and presentation of antigens but also cytokine secretion and subsequently the activation of lymphocyte-based specific immune response.

\section{Phagocytosis}

A process in which invading bacteria are internalized and killed by phagocytes. Phagocytosis initiates the processing and presentation of foreign antigens and the induction of cytokine secretion leading to lymphocyte activation.

Separated in-vivo stimulated leukocytes

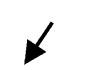

Incubation with inactivated $A$. salmonicida

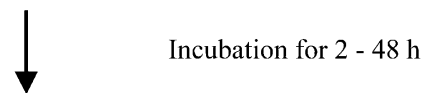

Detection of phagocytosed bacteria after histochemical staining
Incubation with

PKH-26 labelled A. salmonicida

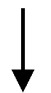

Detection of phagocytosed bacteria using flow cytometry

to determine

phagocytotic activity of trout leukocytes after in-vivo stimulation

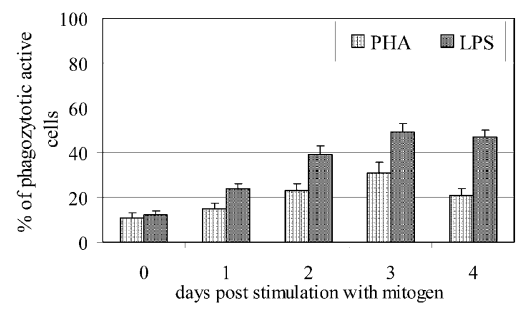

Reactivity of trout head kidney leukocytes in a phagocytosis assay after in-vivo stimulation with different mitogens

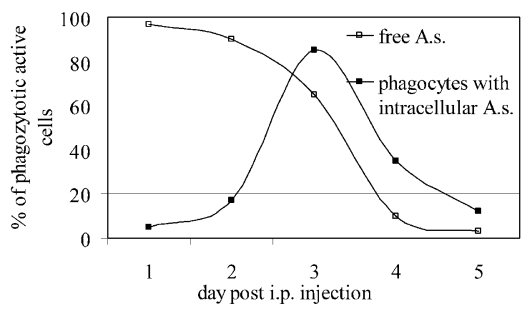

Phagocytosis of $A$. salmonicida in trout peritoneal cavity by peritoneal leukocytes. At day 6 neither free A. salmonicida nor phagoctes with intracellular bacteria were detected (not shown)

Fig. 5. Suggested methods to determine phagocytotic activity of fish leukocytes. After in vivo stimulation leukocytes are exposed to unlabeled (Hardie et al., 1994) or PKH26 labeled A. salmonicida, (Köllner et al., 2001). Phagocytosis can be determined by histochemical staining followed by microscopy or flow cytometry as shown in the examples. Note the increased phagocytosis after stimulation with LPS and the rapid clearance of bacteria in the peritoneal cavity. 


\section{Respiratory burst}

is the process of production of free $\mathrm{O}^{-}$and NO radicals in monocytes and granulocytes to kill phagocytosed intracellular or extracellular bacteria.

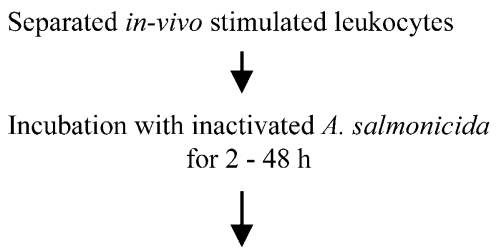

Addition of nitro-tetrazolium blue

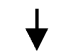

Measurement of OD

in spectrophotometer

to determine

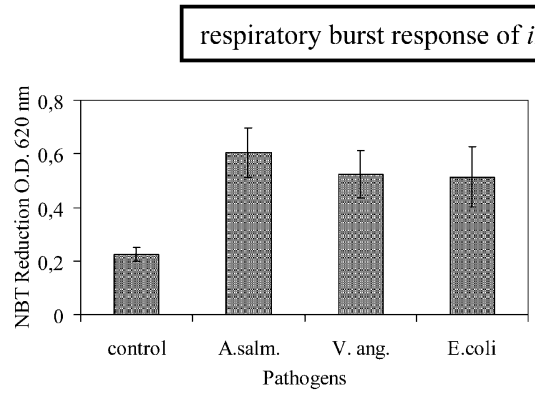

Respiratory burst of trout head kidney leukocytes after in-vivo stimulation with different bacteria

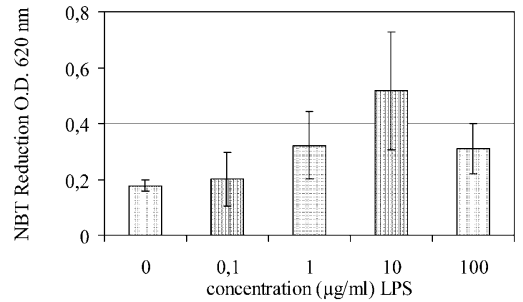

Respiratory burst of trout head kidney leukocytes after in-vivo stimulation with increasing doses of LPS

Fig. 6. A method to determine respiratory burst. After in vivo stimulation leukocytes are cultivated with different bacteria to induce respiratory burst (Solem et al., 1995). Note the increased response of the in vivo primed leukocytes after in vitro restimulation with A. salmonicida.

The methods to measure phagocytosis are shown in Fig. 5. Sensitivity of both methods has been shown by Solem et al. (1995) who demonstrated a dose-dependent stimulation of phagocytosis using different concentrations of LPS.

\section{Respiratory burst}

Invading microorganisms are killed by free oxygen and nitrogen radicals; either extracellularly, without prior phagocytosis, or intracellularly after phagocytosis (Secombes and Fletcher, 1992). This antigen-nonspecific immune function is executed by macrophages and granulocytes (Fig. 1). During respiratory burst, toxic oxygen products such as superoxide and hydrogen peroxide are produced and released into the surrounding tissue (Jang et al., 1995; Secombes, 1990). Inhibition of this process by immunotoxic substances leads to a prolonged surveillance of invading bacteria or fungi followed by an increased growth and subsequently leading to an increase of the pathogenic influence on normal physiology resulting in increasing disease with possibly fatal outcome (Fig. 1). Most methods measuring respiratory burst are based on the detection of intracellular superoxide production using tetrazolium salts (Fig. 6). 


\section{Antibody secretion}

Antibodies are produced by B-lymphocytes after stimulation with antigenic peptides presented in association with MHC class II molecules on accessory cells. Cytokines secreted by macrophages and possibly $\mathrm{T}_{\text {(helper?) }}$ cells, which have not yet been clearly identified in fish, act as co-stimulatory molecules (Fig. 1) (Cain et al., 2002; Christie, 1997). Strong antigens, like bacterial LPS induce an antibody response by direct activation of B-lymphocytes (Ellis, 1997). In fish, secreted antibodies in serum and mucus are of the immunoglobulin class M ( $\operatorname{IgM}$ ) only (An- dersson et al., 1995; Castillo et al., 1993). After binding of antigens, different effector functions are initiated: enhanced phagocytosis of the opsonized antigens by macrophages, complementdependent cytolysis, antibody-dependent cell-mediated cytotoxicity via Fc-receptors on natural cytotoxic cells, and virus neutralization by blocking entry into susceptible cells (Fig. 1) (Kaattari et al., 2002; Boudinot et al., 1998; Hattenberger-Baudouy et al., 1995; Emmenegger et al., 1995; Anderson and Jeney, 1992; Sharp et al., 1992). Inhibition of various functions of antibodies therefore results in an increased susceptibility to infectious diseases.

\section{Secretion of antigen-specific antibodies}

Specific immune response of $\operatorname{sgM}^{+}$B-lymphocytes, secreting antigen specific antibodies after presentation of foreign antigenic peptides via MHC class II by macrophages
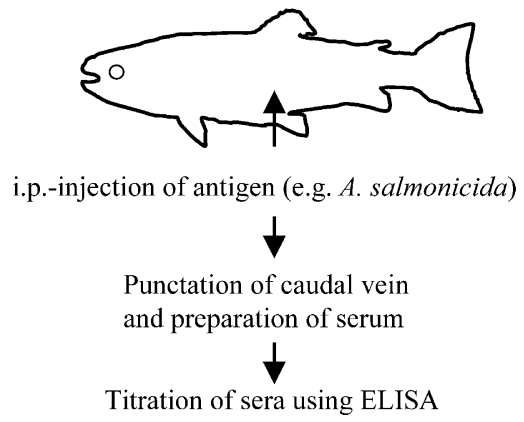

to determine

antibody response of trout after single i.p.-injection of $A$. salmonicida

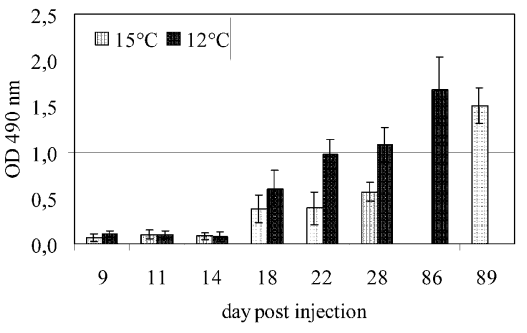

Temperature-dependent antibody response after i.p.-injection of inactivated $A$. salmonicida

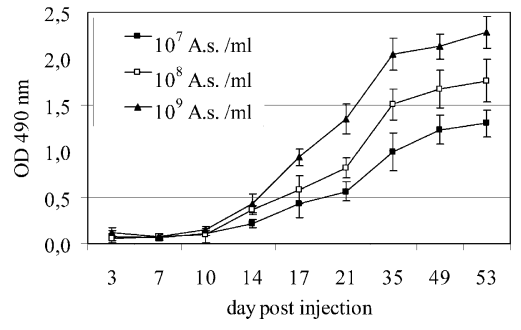

Dose-dependent antibody response after i.p.-injection of different amounts of inactivated $A$. salmonicida

Fig. 7. Detection of antigen-specific antibodies in fish sera. High titers of antigen-specific antibodies can be detected after a single injection of A. salmonicida (Köllner and Kotterba, 2002). A possible influence of an aquatic pollutant can be determined in pre- or co-exposure experiments. The influence of environmental temperature and antigen dose on the level of specific antibodies shown in the examples indicates the sensitivity of this method. 


\section{Specific cell-mediated cytotoxicity}

Specific immune response of $\operatorname{sigM}^{-}$T-Lymphocytes which kill allogeneic or infected isogenic cells after presentation of foreign antigenic peptides via MHC class I molecules

\section{$\underline{\text { Sensitization against allogeneic cells }}$}

Injection of RTG-2 cells

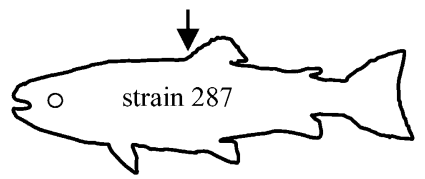

Incubation of isolated PBL with

erythrocytes from different trout clones $\underline{\text { Sensitization against viral protein }}$

Injection of DNA encoding IHNV G-Protein

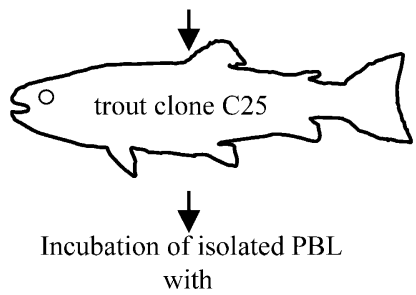

different IHNV infected cells

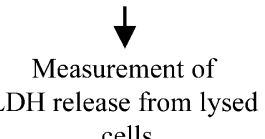

to determine

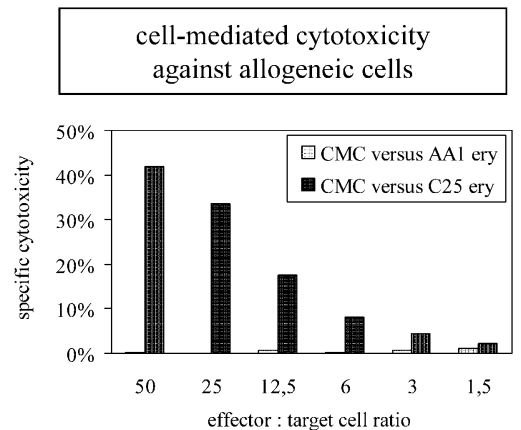

Cell-mediated cytotoxicity of trout leukocytes from strain 287 previously sensitized with allogeneic RTG- 2 cells $(\mathrm{MHC} \mathrm{I}=\mathrm{C} 25, \neq 287$ $\neq \mathrm{AA} 1$ ) against $\mathrm{MHC}$ I matching (strain C25) and missmatching (strain AAl) erythrocytes

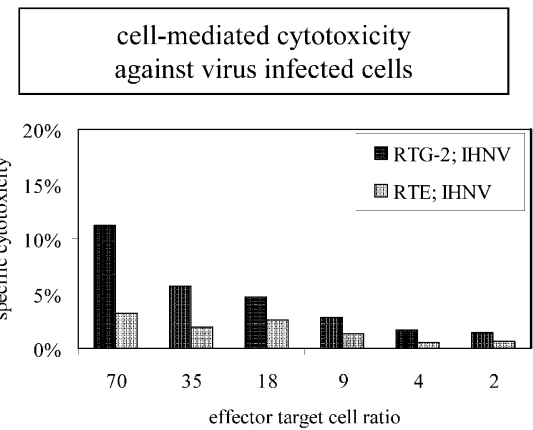

Cell-mediated cytotoxicity of trout leukocytes from strain C25 previously immunized with IHNV-DNA against IHNV infected MHC I matching (RTG-2, MHC I $=\mathrm{C} 25)$ and missmatching (RTE MHC I $\neq \mathrm{C} 25$ ) cells

Fig. 8. Determination of specific cell-mediated cytotoxicity after in vivo sensitization with allogeneic cells or virus antigens (Fischer et al., 1998). A possible impact of aquatic pollutants can be determined in pre- or co-exposure experiments. The diagrams show examples of the specific response against allogeneic or virus infected cells of previously sensitized trout.

One of the available tests used for the detection of antigen-specific antibody secretion is based on an ELISA after a single immunization with bacteria (Aeromonas salmonicida) (Köllner and Kotterba, 2002) (Fig. 7). The an- tibody response was strongly temperature-dependent (Fig. 7). Application of different amounts of inactivated bacteria resulted in direct dose-dependent antibody secretion (Gudmundsdottir et al., 1995). 


\section{Specific cell mediated cytotoxicity}

Specific cell mediated cytotoxicity which has only recently been shown in fish is involved in the immune response against viral infection and cancer cells (reviewed by Nakanishi et al., 2002; Dijkstra et al., 2001). Sensitized sIgM $^{-}$ lymphocytes kill allogeneic cells or virus infected fish cells (Somamoto et al., 2000; Fischer et al., 1998; Stuge et al., 1997, 1995). In vitro assays of cell-mediated cytotoxicity are based on the release of hemoglobin from allogeneic erythrocytes (Fischer et al., 1998) of lactate dehydrogenase from allogeneic or virus infected cells (Fischer et al., 1998) or on the release of ${ }^{51} \mathrm{Cr}$ from labeled target cells (Somamoto et al., 2000).

The assay system is described in Fig. 8. For the detection of specific cell-mediated cytotoxicity against virus infected cells, a system of MHC class I matching effector and target cells is required (MHC class I restriction of cytotoxicity). Preferably, clonal fish and target cell lines with a known MHC class I genotype are used. Furthermore, the use of clonal or inbred fish is required to obtain comparable data from differently treated groups. As shown in Fig. 8 the cytotoxic reaction is strongly specific and depends on prior sensitization.

\section{Concluding remarks}

In this review a number of methods to evaluate immunotoxic effects of pollutants on single and complex immune functions are suggested. Commonly used immunotoxicological tests assess the primary response of affected immune parameters. In contrast, the tests suggested here are based on the determination of the effects of pollutants on in vivo stimulated immune functions in a defined immune response to standardized antigens or stimulants. Using this approach, the possible toxic effect of an aquatic pollutant can be estimated

1. after pretreatment of fish with a pollutant (pre-exposure) followed by an in vivo stimulation to evaluate in vitro the ability of immune cells to be activated and proliferate in response to immune stimulants (antigens, mitogens, infectious microorganism)
2. during treatment of fish with a pollutant together with an in vivo stimulation (co-exposure) to determine in vitro the ability to respond after activation/stimulation to immune stimulants (antigens, mitogens, infectious microorganism)

Both approaches provide an evaluation of immunotoxic effects of pollutants on the immune responses to defined pathogens or stimulants. The suitability of the suggested tests as 'biomarkers' for pollutant-induced immunosuppression requires further investigation and standardization of the assays.

\section{References}

Ainsworth, A.J., 1992. Fish granulocytes: morphology, distribution and function. Ann. Rev. Fish Dis. 2, 123-148.

Anderson, D.P., Jeney, G., 1992. Immunostimulants added to injected Aeromonas salmonicida bacterin enhance the defense mechanisms and protection in rainbow trout (Oncorhynchus mykiss). Vet. Immunol. Immunopathol. 34 (3-4), 379-389.

Andersson, E., Peixoto, B., Tormanen, V., Matsunaga, T., 1995. Evolution of the immunoglobulin M constant region genes of salmonid fish, rainbow trout (Oncorhynchus mykiss) and Arctic charr (Salvelinus alpinus): implications concerning divergence time of species. Immunogenetics 41 (5), 312-315.

Anderson, D.P., 1997. Adjuvants and immunostimulants for enhancing vaccine potency in fish. Dev. Biol. Stand. 90, 257-265 review.

Arkoosh, M.R., Casillas, E., Clemons, E., Kagley, A.N., Olson, R., Reno, P., Stein, J.E., 1998. Effect of pollution on fish diseases: potential impact on salmonid populations. J. Aquatic Anim. Health 10, 182-190.

Beaman, J.R., Finch, R., Gardner, H., Hoffmann, F., Rosencrance, A., Zelikoff, J.T., 1999. Mammalian immunoassays for predicting the toxicity of malathion in a laboratory fish model. J. Toxicol. Environ. Health A 56 (8), 523-542.

Blohm, U., Siegl, E., Köllner, B. Rainbow trout (Oncorhynchus mykiss) $\mathrm{sIgM}^{-}$leucocytes secrete an interleukin-2 like growth factor after mitogenic stimulation in-vitro. Fish Shellfish Immunol., accepted for publication.

Bly, J.E., Quiniou, S.M., Clem, L.W., 1997. Environmental effects on fish immune mechanisms. Dev. Biol. Stand. 90, 33-43 review.

Boudinot, P., Blanco, M., de Kinkelin, P., Benmansour, A., 1998. Combined DNA immunization with the glycoprotein gene of viral hemorrhagic septicemia virus and infectious hematopoietic necrosis virus induces double-specific protective immunity and nonspecific response in rainbow trout. Virology 249 (2), 297-306. 
Cain, K.D., Jones, D.R., Raison, R.L., 2002. Antibody-antigen kinetics following immunization of rainbow trout (Oncorhynchus mykiss) with a T-cell dependent antigen. Dev. Comp. Immunol. 26 (2), 181-190.

Castillo, A., Sanchez, C., Dominguez, J., Kaattari, S.L., Villena, A.J., 1993. Ontogeny of IgM and IgM-bearing cells in rainbow trout. Dev. Comp. Immunol. 17 (5), 419-424.

Christie, K.E., 1997. Immunization with viral antigens: infectious pancreatic necrosis. Dev. Biol. Stand. 90, 191-199 review.

Dannevig, B.H., Lauve, A., Press, C., Landsverk, T., 1994. Receptor-mediated endocytosis and phagocytosis by rainbow trout head kidney sinusoidal cells. Fish Shellfish Immunol. 4, 3-18.

Dijkstra, J.M., Fischer, U., Sawamoto, Y., Ototake, M., Nakanishi, T., 2001. Exogenous antigens and the stimulation of MHC class I restricted cell-mediated cytotoxicity: possible strategies for fish vaccines. Fish Shellfish Immunol. 11 (6), 437-458.

Ellis, A.E., 2001. Innate host defense mechanisms of fish against viruses and bacteria. Dev. Comp. Immunol. 25 (8-9), 827-839.

Ellis, A.E., 1997. Immunization with bacterial antigens: furunculosis. Dev. Biol. Stand. 90, 107-116 review.

Emmenegger, E., Huang, C., Landolt, M., LaPatra, S., Winton, J.R., 1995. Immune response to synthetic peptides representing antigenic sites on the glycoprotein of infectious hematopoietic necrosis virus. Vet. Res. 26 (5-6), 374-378 review.

Fischer, U., Köllner, B., 1994. Preparation of B-cell and monocyte free thymocyte suspensions. In: Stolen, J.S., Fletcher, T.C., Rowley, A.F., Zelikoff, J.T., Kaattari, S.L., Smith, S.A. (Eds.), Techniques in Fish Immunology III. SOS Publications, Fair Haven, USA, pp. 27-33.

Fischer, U., Ototake, M., Nakanishi, T., 1998. In-vitro cell mediated cytotoxicity against allogeneic erythrocytes in gimbuna crucian carp and goldfish using a non-radioactive assay. Dev. Comp. Immunol. 22, 195-206.

Gudding, R., Lillehaug, A., Evensen, O., 1999. Recent developments in fish vaccinology. Vet. Immunol. Immunopathol. 72 (1-2), 203-212 review.

Gudmundsdottir, S., Magnadottir, B., Gudmundsdottir, B.K., 1995. Effects of antigens from Aeromonas salmonicida ssp. achromogenes on leukocytes from primed and unprimed Atlantic salmon (Salmo salar L.). Fish Shellfish Immunol. 5, 493-504.

Hardie, L.J., Fletcher, T.C., Secombes, C.J., 1994. Effect of temperature on macrophage activation and the production of macrophage activating factor by rainbow trout (Oncorhynchus mykiss) leucocytes. Dev. Comp. Immunol. 18, 57-66.

Hattenberger-Baudouy, A.M., Danton, M., Merle, G., de Kinkelin, P., 1995. Serum neutralization test for epidemiological studies of salmonid rhabdoviruses in France. Vet. Res. (5-6), 512-520.

Hong, S., Zou, J., Crampe, M., Peddie, S., Scapigliati, G., Bols, N., Cunningham, C., Secombes, C.J., 2001. The production and bioactivity of rainbow trout (Oncorhynchus mykiss) recombinant IL-1 beta. Vet. Immunol. Immunopathol. 81 (1-2), 1-14.

Jang, S.I., Hardie, L.J., Secombes, C.J., 1995. Elevation of rainbow trout Oncorhynchus mykiss macrophage respiratory burst activity with macrophage-derived supernatants. J. Leukoc. Biol. 57 (6), 943-947.

Jones, S.R., 2001. The occurrence and mechanisms of innate immunity against parasites in fish. Dev. Comp. Immunol. 25 (8-9), 841-852.

Kaattari, S.L., Zhang, H.L., Khor, I.W., Kaattari, I.M., Shapiro, D.A., 2002. Affinity maturation in trout: clonal dominance of high affinity antibodies late in the immune response. Dev. Comp. Immunol. 26 (2), 191-200.

Keil, D., Luebke, R.W., Ensley, M., Gerard, P.D., Pruett, S.B., 1999. Evaluation of multivariate statistical methods for analysis and modeling of immunotoxicology data. Toxicol. Sci. 51 (2), 245-258.

Keil, D., Luebke, R.W., Pruett, S.B., 2001. Quantifying the relationship between multiple immunological parameters and host resistance: probing the limits of reductionism. J. Immunol. 167 (8), 4543-4552.

Köllner, B., Blohm, U., Kotterba, G., Fischer, U., 2001. Characterisation of a monoclonal antibody recognising rainbow trout (Oncorhynchus mykiss) monocytes. Fish Shellfish Immunol. 11, 127-142.

Köllner, B., Kotterba, G., 2002. Temperature dependent activation of leukocyte populations of rainbow trout, Oncorhynchus mykiss, after intraperitoneal immunisation with Aeromonas salmonicida. Fish Shellfish Immunol. 12 (1), 35-48.

Langezaal, I., Coecke, S., Hartung, T., 2001. Whole blood cytokine response as a measure of immunotoxicity. Toxicol. In-Vitro 15 (4-5), 313-318.

Luebke, R.W., Hodson, P.V., Faisal, M., Ross, P.S., Grasman, K.A., Zelikoff, J., 1997. Aquatic pollution-induced immunotoxicity in wildlife species. Fundam. Appl. Toxicol. 37 (1) $1-15$.

Luster, M.I., Portier, C., Pait, D.G., White, K.L. Jr., Gennings, C., Munson, A.E., Rosenthal, G.J., 1992. Risk assessment in immunotoxicology. I. Sensitivity and predictability of immune tests. Fundam. Appl. Toxicol. 18 (2), $200-210$

Luster, M.I., Portier, C., Pait, D.G., Rosenthal, G.J., Germolec, D.R., Corsini, E., Blaylock, B.L., Pollock, P., Kouchi, Y., Craig, W., 1993. Risk assessment in immunotoxicology. II. Relationships between immune and host resistance tests. Fundam. Appl. Toxicol. 21 (1), $71-$ 82.

Magnadottir, B., Jonsdottir, H., Helgason, S., Bjornsson, B., Jorgensen, T.O., Pilström, L., 1999. Humoral immune parameters in Atlantic cod (Gadus morhua L.) I. The effects of environmental temperature. Comp. Biochem. Physiol. B Biochem. Mol. Biol. 122 (2), 173-180.

Marsden, J.M., Vaughan, L.M., Foster, T.J., Secombes, C.J., 1995. Proliferative response of rainbow trout, Oncorhynchus mykiss, $\mathrm{T}$ and $\mathrm{B}$ cells to antigens of 
Aeromonas salmonicida. Fish Shellfish Immunol. 5, 199-210.

Nakanishi, T., Fischer, U., Dijkstra, J.M., Hasegawa, S., Somamoto, T., Okamoto, N., Ototake, M., 2002. Cytotoxic $\mathrm{T}$ cell function in fish. Dev. Comp. Immunol. 26 (2), $131-139$.

Novoa, B., Figueras, A., Secombes, C.J., 1996a. Effects of in vitro addition of infectious pancreatic necrosis virus (IPNV) on rainbow trout Oncorhynchus mykiss leucocyte responses. Vet. Immunol. Immunopathol. 51 (3-4), 365-376.

Novoa, B., Figueras, A., Ashton, I., Secombes, C.J., 1996b. In vitro studies on the regulation of rainbow trout (Oncorhynchus mykiss) macrophage respiratory burst activity. Dev. Comp. Immunol. 20 (3), 207-216.

Rycyzyn, M.A., Wilson, M.R., Bengten, E., Warr, G.W., Clem, L.W., Miller, N.W., 1998. Mitogen and growth factor-induced activation of a STAT-like molecule in channel catfish lymphoid cells. Mol. Immunol. 35 (2), 127-136.

Sharp, G.J., Pike, A.W., Secombes, C.J., 1992. Sequential development of the immune response in rainbow trout (Oncorhynchus mykiss, Walbaum, 1792) to experimental plerocercoid infections of Diphyllobothrium dendriticum (Nitzsch, 1824). Parasitology 104 (Part 1), 169-178.

Secombes, C.J., 1990. Isolation of salmonid macrophages and analysis of their killing activity. In: Stolen, J.S., Fletcher, T.C., Rowley, A.F., Zelikoff, J.T., Kaattari, S.L., Smith, S.A. (Eds.), Techniques in Fish Immunology. SOS Publications, Fair Haven, USA, pp. 139-154.

Secombes, C.J., Fletcher, T.C., 1992. The role of phagocytes in the protective mechanisms of fish. Annual Rev. Fish Dis. 2, $53-71$.

Smith, D.A., Schurig, G.G., Smith, S.A., Holladay, S.D., 1999. Tilapia (Oreochromis niloticus) and rodents exhibit similar patterns of inhibited antibody production following exposure to immunotoxic chemicals. Vet. Hum. Toxicol. 41 (6), 368-373.

Smith, V.J., Fernandes, J.M., Jones, S.J., Kemp, G.D., Tatner, M.F., 2000. Antibacterial proteins in rainbow trout, Oncorhynchus mykiss. Fish Shellfish Immunol. 10 (3), 243260.

Solem, S.T., Jorgensen, J.B., Robertson, B., 1995. Stimulation of respiratory burst in Atlantic salmon (Salmo salar L.) macrophages by lipopolysaccharide. Fish Shellfish Immunol. 5, 475-491.
Somamoto, T., Nakanishi, T., Okamoto, N., 2000. Specific cell-mediated cytotoxicity against a virus-infected syngeneic cell line in isogeneic ginbuna crucian carp. Dev. Comp. Immunol. 24 (6-7), 633-640.

Stuge, T.B., Miller, N.W., Clem, L.W., 1995. Channel catfish cytotoxic effector cells from peripheral blood and pronephros are different. Fish Shellfish Immunol. 5, 469471.

Stuge, T.B., Yoshida, S.H., Chinchar, V.G., Miller, N.W., Clem, L.W., 1997. Cytotoxic activity generated from channel catfish peripheral blood leukocytes in mixed leukocyte cultures. Cell. Immunol. 177, 154-161.

Twerdok, L.E., Beaman, J.R., Curry, M.W., Zelikoff, J.T., 1996. Health status and monitoring in an aquatic model (Oryzias latipes) using in immunotoxicological testing. In: Stolen, J.S., Fletcher, T.C., Bayne, C.J., Secombes, C.J., Zelikoff, J.T., Twerdok, L.E., Anderson, D.P. (Eds.), Modulators of Immune Response: The Evolutionary Trail. SOS Publications, Fair Haven, NJ, pp. 417-424.

Verburg-Van Kemenade, B.M., Saeij, J.P., Flik, G., Willems, P.H., 1998. $\mathrm{Ca}^{2+}$ signals during early lymphocyte activation in carp Cyprinus carpio L. J. Exp. Biol. 201, 591-598.

Walker, C.H., 1998. Biomarker strategies to evaluate the environmental effects of chemicals. Environ. Health Perspect. 106 (Suppl. 2), 613-620.

Zapata, A.G., Varas, A., Torroba, M., 1992. Seasonal variations in the immune system of lower vertebrates. Immunol. Today 13 (4), 142-147.

Zapata, A., Amemiya, C.T., 2000. Phylogeny of lower vertebrates and their immunological structures. Curr. Top. Microbiol. Immunol. 248, 67-107 review.

Zelikoff, J.T., Bowser, D., Squibb, K.S., Frenkel, K., 1995. Immunotoxicity of low level cadmium exposure in fish: an alternative animal model for immunotoxicological studies. J. Toxicol. Environ. Health 45 (3), 235-248.

Zelikoff, J.T., 1998. Biomarkers of immunotoxicity in fish and other non-mammalian sentinel species: predictive value for mammals? Toxicology 129 (1), 63-71 review.

Zelikoff, J.T., Raymond, A., Carlson, E., Li, Y., Beaman, J.R., Anderson, M., 2000. Biomarkers of immunotoxicity in fish: from the lab to the ocean. Toxicol. Lett. 112-113, 325-331 review. 